\title{
LINGUISTIC MEANING, NONLINGUISTIC “EXPRESSION," AND THE MULTIPLE VARIANTS OF EXPRESSIVISM: A REPLY TO PROFESSORS ANDERSON AND PILDES
}

\author{
MATTHEW D. ADLER ${ }^{\dagger}$
}

The term "expression" is profoundly ambiguous, and so, too, is the phrase "expressive theory of law." An "expressive theory of law" might mean (1) a theory of law focused on the linguistic meaning of legal decisions; (2) a theory of law focused on the Gricean nonlinguistic meaning of legal decisions; (3) a theory of law focused on the cultural impact of legal decisions; or (4) a theory of law focused on the attitudes "expressed" by legal decisions, where a decision can "express" a given attitude without possessing a linguistic meaning, a Gricean nonlinguistic meaning, or a cultural impact. ${ }^{1}$ My article, Expressive Theories of Law: A Skeptical Overview, ${ }^{2}$ explicated and criticized "expressive theories of law" in the first sense just described. I was quite careful to say that I would not be discussing "expressive theories of law" understood in any other sense-that theories focused on some feature of legal decisions other than linguistic meaning lay outside the scope of my scholarly inquiry, and that my article was not intended either to challenge or to endorse such theories.

I am therefore in agreement with Professors Anderson and Pildes when they state that " $[t]$ o a large extent, the target Adler attacks is not one we wish to defend." Anderson and Pildes go on to suggest that "[g]iven our fundamentally different understanding of the concept of

\footnotetext{
${ }^{\dagger}$ Assistant Professor, University of Pennsylvania Law School. Many thanks to Brian Bix for his comments. All errors are my own.

${ }^{1}$ See Matthew D. Adler, Expressive Theories of Law: A Skeptical Overview, 148 U. PA. L. REv. 1363, 1384-87, 1498-1501 (2000) [hereinafter Skeptical Overview] (discussing nonlinguistic variants of "expressivism"); id. at 1387-1498 (clarifying and criticizing the linguistic variant).

${ }^{2} I d$.

s See, e.g., id. at 1387 ("[T] he focus of this Article will be upon linguistic meaning."); id. at 1498 ("[M]y focus [in this Article] has been on genuine expressive theories in the linguistic sense.").

${ }^{4}$ Elizabeth S. Anderson \& Richard H. Pildes, Expressive Theories of Law: A General Restatement, 148 U. PA. L. REv. 1503, 1564 (2000) [hereinafter General Restatement].
} 
expression," they and I have failed to join issue. ${ }^{5}$ I concur with the suggestion: we have failed to join issue. General Restatement is an impressive contribution to the scholarly literature, and one that will materially advance the debate about "expressive theories of law." But this work is not so much a rebuttal of my own article as a confirmation of that article, or at least immaterial to my article. I argue that the linguistic meaning of a legal official's action is not foundationally relevant to the moral status of that action; Anderson and Pildes do not claim to the contrary (with one possible exception, to be discussed below), and instead argue that the attitudes "expressed" by the action in some nonlinguistic sense are foundationally relevant to its moral status.

Anderson and Pildes also say that "Adler clearly would continue to be troubled by expressive [nonlinguistic] theories of law." This is incorrect. I did not analyze or criticize nonlinguistic theories in Skeptical Overview, and I will not do so here. I do not have time or space for that in this brief Reply, and, in any event, criticizing the nonlinguistic theory presented by Anderson and Pildes in General Restatement would not serve the purpose of this Reply. My purpose, here, is to rehabilitate Skeptical Overview from any damage done by the Anderson and Pildes contribution. Since we mean different things by "expressive theories of law," the damage done (again, with one possible exception, to be discussed below) is nil.

Lest the reader suspect me of tendentiousness, let me be a bit more precise. I will call "expression" in the Adler sense $M$-expression and "expression" in the Anderson/Pildes sense ER-expression." An action is $M$-expressive if it possesses linguistic meaning-more precisely, if it possesses sentence meaning or speaker's meaning, concepts I analyzed at length in Skeptical Overview. ${ }^{8}$ As I further explained in

\footnotetext{
${ }^{5}$ Id. at 1570 .

${ }^{6}$ Id. at 1564 .

7 The letter " $M$ " stands for my first name, while the letters " $E$ " and " $R$ " stand for the first names of Professors Anderson and Pildes. I have used these letters, rather than letters referring to last names, to avoid the double occurrence of "A." And I have used letters referring to our names, rather than letters referring to features of our theories (for example, calling my theory an " $L$ " theory, for linguistic meaning), because I can think of no short sequence of letters that summarizes what makes an action "expressive" within the Anderson/Pildes theory.

${ }^{8}$ See Skeptical Overview, supra note 1, at 1387-89, 1392-96. I further argued that plausible $M$-expressive theories focus on sentence meaning, not on speaker's meaning alone or on speaker's meaning plus sentence meaning. See id. at 1389-96. I therefore focused my critical attention, in the remainder of the article, upon sentence-meaning theories. See id. at 1396-1499. In short, the article taken as a whole defends the following syllogism: (I) M-expressivism is true only if sentence-meaning expressivism is true;
} 
the article, an $M$-expressive or linguistic-meaning theory of law is a theory such that the set of moral factors determining the status of a legal official's action includes at least one $M$-expressive factor. An $M$ expressive factor is a moral factor such that actions lacking $M$ expressive meaning, i.e., linguistic meaning, must fare identically with respect to that factor.'

Anderson and Pildes state quite clearly that an action can be $E R$ expressive without being $M$-expressive. As they put it, "The concept of expression should be contrasted with causation, on the one hand, and communication [linguistic meaning], on the other." ${ }^{10}$ Again:

Expression must also be distinguished from communication. To express a mental state requires only that one manifest it in speech or action.... The shoplifter may express her intention to get away with stealing a purse in her furtive glances. But she hardly intends to communicate this intention.

Once more:

[Our] account of expressive theories of law, morality, and practical reason is concerned with the attitudes and ideas that individuals and institutions express, not just with the attitudes and ideas that they communicate. To express a state of mind is, among other things, to manifest it in action. To communicate a state of mind is to act with the intention of inducing others to recognize that state of mind by recognizing that very communicative intention. Communicative acts are only a small subset of all expressive acts. ${ }^{12}$

One might object that these particular quotations rule out an equivalence between ER-expression and speaker's meaning, but not the (possible) equivalence between ER-expression and linguistic meaning, i.e., speaker's meaning or sentence meaning. However, I see nothing in General Restatement to suggest that an act of ER-expression must possess a sentence meaning if it lacks a speaker's meaning, and plenty to suggest that Anderson and Pildes deny an equivalence between $E R$ expression and "communication" (the term they use for what I am calling "linguistic meaning"), whether understood as the disjunct of speaker's meaning and sentence meaning or in some other way. ${ }^{13}$ For

(II) sentence-meaning expressivism is not true; thus, (III) $M$-expressivism is not true.

See id. at 1401-09 (explaining the components of an "expressive" theory of law, with "expressive" used to denote linguistic meaning).

${ }^{10}$ General Restatement, supra note 4, at 1508.

${ }^{11}$ Id.

${ }^{12} I d$. at 1565 (citation omitted).

13 See, e.g., id. at 1524 (stating that "the public meaning of an action is not" determined by its sentence meaning); id. at 1525 ("[Expressive] meanings do not actually 
example, the furtive act of shoplifting they describe ${ }^{14}$ is not linguistically meaningful ("communicative") in any way. The actor does not intend to cause some effect in the viewer by the viewer's recognition of that very intention (speaker's meaning), the actor is not invoking a convention for performing speech-acts (sentence meaning), and the act would not be seen as "communicative" pursuant to the theory of linguistic meaning sketched out at the end of General Restatement. ${ }^{15}$

In short, an act can be $E R$-expressive without being $M$-expressive. Conversely, it seems, an act can be $M$-expressive without being $E R$ expressive. The linguistically meaningful action of uttering "I promise to buy the car" need not express any attitude (although it may necessarily presuppose various attitudes, such as beliefs about the car's current ownership or the speaker's preference for the car over some alternatives). Similarly, the linguistically meaningful action of uttering "pass the salt" is a directive rather than a descriptive utterance, ${ }^{16}$ and therefore need not express a belief on the speaker's part or, it seems, any other attitude of hers. Even if this is untrue-even if every $M$ expression is an $E R$-expression-it is not true that every $E R$-expression is an $M$-expression. Therefore, the two categories are nonequivalent.

At the risk of repetition, let me restate this point in less technical terms. My article is focused upon the linguistic meaning of governmental action. Anderson and Pildes are focused upon "expression" in some sense other than linguistic meaning. A governmental action is "expressive," in my sense, if it possesses linguistic meaning. A governmental action will be "expressive," in the Anderson/Pildes sense, even if it lacks linguistic meaning, as long as it meets various other conditions they describe for "expressing" an attitude. (For example, an action that lacks linguistic meaning will still "express" an attitude in the Anderson/Pildes sense if it is motivated by the attitude, or if the attitude is in some way recognizable in the action. $)^{17}$ For short, I call "expression" in my sense $M$-expression, and "expression" in the Anderson/Pildes sense ER-expression. It is arguable that some governmental actions are $M$-expressive but not $E R$-expressive; and, in any event, some governmental actions are $E R$-expressive without being $M$ expressive. Anderson and Pildes quite clearly avow the latter proposition.

\footnotetext{
have to be recognized by the community....").

${ }^{14}$ See id. at 1508 .

${ }^{15}$ See id. at 1570-75 (presenting non-Gricean theory of linguistic meaning).

${ }^{16}$ See Skeptical Overview, supra note 1, at 1395-96 (distinguishing between different types of linguistic meaning).

${ }^{17}$ See General Restatement, supra note 4, at 1506-08, 1524-27.
} 
Relatedly, an ER-expressive theory of law is not necessarily an $M$ expressive theory of law. (This will be true as long as some ERexpressive actions are not $M$-expressive, even if all $M$-expressive actions are ER-expressive.) An ER-expressive theory of law is a theory such that the moral factors determining the moral status of a legal official's action include at least one ER-expressive factor, where an $E R$ expressive factor is a factor such that actions lacking $E R$-meaning must fare identically with respect to that factor. Clearly, an ER-expressive factor is not an $M$-expressive factor. ${ }^{18}$ For example, a factor that prohibits persons from ER-expressing "contempt" can be infringed by an action that lacks linguistic meaning but still ER-expresses contemptbecause the actor was in fact animated by an attitude of contempt, or because he was not thus animated but he nonetheless (negligently) performed an action that is properly "interpreted" or "recognized" as contemptuous. The same is generally true of factors that prohibit or require persons to $E R$-express various attitudes: linguistically meaningless actions are not guaranteed to fare the same with respect to such factors, since some linguistically meaningless actions will infringe them while others will not, and therefore they are not $M$-expressive.

It follows that an ER-expressive theory need not be an $M$ expressive theory. More precisely, (1) an ER-expressive theory that contains only $E R$-expressive factors cannot be an $M$-expressive theory (since $E R$-factors are not $M$-factors), and (2) an $E R$-expressive theory that is not exclusively composed of ER-expressive factors may be an Mexpressive theory, but need not be. (This second kind of ER-expressive theory will be an $M$-expressive theory if it contains at least one $M$ expressive factor along with its $E R$-expressive factors, but it could also contain some $E R$-expressive factors, some nonexpressive factors, and no $M$-expressive factors and thus fail to be an $M$-expressive theory.) Let us call the first kind of ER-expressive theory a robust ER-expressive theory of law, and the second kind a weak ER-expressive theory of law.

\footnotetext{
${ }^{18}$ More precisely, I should say that an ER-expressive factor need not be an $M$ expressive factor. If every linguistically meaningful action is an instance of $E R$ expression, then any $M$-expressive factor $F$ will be $E R$-expressive (since actions lacking $E R$-expressive meaning will lack $M$-expressive meaning, and will fare the same with respect to $F$. Henceforth, I will use the term "ER-expressive factor" to mean a factor that (a) is not an $M$-expressive factor (since some linguistically meaningless actions fare differently with respect to it), but (b) is an ER-expressive factor (since all actions lacking ER-expressive meaning fare the same with respect to it).

${ }_{19}$ See General Restatement, supra note 4, at 1525 ("Expressive meanings are socially constructed.... Although these meanings do not actually have to be recognized by the community, they have to be recognizable by it, if people were to exercise enough interpretive self-scrutiny.").
} 
Most of General Restatement is devoted to defending an ERexpressive theory of law. What kind is it? Do Anderson and Pildes intend to defend a robust ER-expressive theory, such that the moral status of a legal official's action is exclusively a function of what that action ER-expresses? At certain points, that does seem to be their intention. They state early in their article that "what makes an action morally right depends on whether it expresses the appropriate valuations of (that is, attitudes toward) persons ${ }^{\text {"20 }}$ and, a bit later, make the following statement:

A normative theory of action is an expressive theory if it evaluates actions in terms of how well they express certain intentions, attitudes, or other mental states. An expressive theory of action must therefore (a) prescribe norms for regulating the adoption of certain mental states, and $(b)_{21}$ require actions and statements to express these states adequately.

Note that if Anderson and Pildes successfully defend a robust ERexpressive theory of law, then they have necessarily confirmed my claim in Skeptical Overview. If the correct moral theory of legal decision is a robust ER-expressive theory, then it logically follows that the correct moral theory of legal decision is not an $M$-expressive theory. This is precisely what I claimed in Skeptical Overview-that the correct moral theory of legal decision is not an $M$-expressive theory.

At other points in the Anderson and Pildes piece, however, it seems that they merely mean to defend a weak $E R$-expressive theory. For example, they make the following statement at the beginning of the part of General Restatement devoted specifically to "Expressive Theories of Law: The Expressive Dimensions of Constitutional Law":

One could try to offer an expressive theory of law (or morality) as a comprehensive theory of legal (or moral) wrongs. Such a theory would account for both expressive and nonexpressive harms in ultimately expressivist terms. We do not attempt such an ambitious task here.... Instead, the remaining discussion will focus on issues of structure, equality, and rights in some exemplary areas of constitutional law.

Assume that Anderson and Pildes merely intend to defend a weak ERexpressive theory of law, and that they succeed in doing so in General

${ }^{20}$ Id. at 1504 .

${ }^{21}$ Id. at 1508-09; see also id. at 1570 ("Expressive theories constrain action by constraining the ways in which we take various moral factors into consideration. They specify the form of normatively required constraints on action, not the contents of specific moral factors." (emphasis added)).

${ }_{22} I d$. at 1531 . 
Restatement. Then, General Restatement does not confirm my claim in Skeptical Overview, but it is still immaterial to my article, since the existence of some ER-expressive factors neither precludes, nor entails, the existence of some $M$-expressive factors. More precisely, General $R e-$ statement will be immaterial to my article unless Anderson and Pildes show not merely (1) that some ER-expressive factors exist, but also (2) that at least one $M$-expressive factor exists. Unless Anderson and Pildes succeed in defending a hybrid theory of legal decision, which is both (weakly) ER-expressive in containing some $E R$-expressive factors, and $M$-expressive in containing some $M$-expressive factors, their article can do no damage to my own.

Do Anderson and Pildes intend to defend a hybrid theory of legal decision-one that is both ER-expressive and $M$-expressive-and if so, do they succeed in this intention? Before addressing this question, let me clear up one crucial misconception that Anderson and Pildes seem to have about Skeptical Overview. One can draw a distinction between weak and robust $M$-expressive theories that precisely parallels the distinction already articulated between weak and robust $E R$ expressive theories. A weak $M$-expressive theory of law is a moral theory such that some of the moral factors governing legal decisions are $M$-expressive factors. A robust $M$-expressive theory of law is a moral theory such that all of the moral factors governing legal decisions are $M$-expressive factors. Anderson and Pildes apparently think that Skeptical Overview uses the term "expressive theory of law" to mean a robust $M$-expressive theory. To quote: "Adler thinks expressive theories of law and morality are concerned only with linguistic utterances or their equivalents ...." ${ }^{23}$ Again:

Adler commits a simple but fundamental error in construing expressive theories of law, morality, and reason as concerned only with communicative acts. In his view, expressive theories of law must by definition have nothing to say about action that is not intended to communicate a particular idea-actions that... Adler labels as expressively "meaningless."...

$\cdots$

[But a]ny normative theory that concerns itself only with communication would be peculiarly narrow. No expressivist writing of which we are aware rests on this truncated view. ${ }^{24}$

With all respect, it is Anderson and Pildes who have made a "simple but fundamental error" in their reading of Skeptical Overview. I was

\footnotetext{
${ }^{23}$ Id. at 1567 .

${ }^{24}$ Id. at $1565,1568$.
} 
quite clear that by "expressive theory" I meant to refer to weak Mexpressive theories as well as robust $M$-expressive theories, ${ }^{25}$ and indeed my analysis focused almost exclusively on weak rather than robust theories since the latter are so obviously wrong. ${ }^{26}$ Understand that a weak $M$-expressive theory will include both $M$-expressive factors and other factors. Such a theory is not "concern[ed] ... only with communication, ${ }^{27}$ nor is it true that such a theory must be neutral between linguistically meaningless acts-that it "must by definition have nothing to say about [noncommunicative] action ${ }^{28}$ - since linguistically meaningless acts can fare differently with respect to non- $M$ expressive factors and therefore, all things considered, with respect to the theory. ${ }^{29}$

By misconstruing my definition of "expressive theory," Anderson and Pildes trivialize the importance of my article. They see the article as attacking a straw man-robust $M$-expressive theories of law-and thus as making no real contribution to the debate about expressivism. But my article attacks a type of moral theory of legal decisions that is hardly a straw man, namely weak $M$-expressive theories: theories that give some relevance, if not conclusive relevance, to the linguistic meaning of legal officials' actions. As I demonstrated in Skeptical Overview, numerous legal scholars (in the areas of punishment theory, the

${ }^{25}$ See Skeptical Overview, supra note 1, at 1404-09. Here is the precise definition of "expressive theory" that I offered:

An "expressive moral theory" is a theory such that the moral factors $F_{1} \ldots F_{n}$ that collectively determine the moral status of an action ... include at least one expressive factor. A moral factor $F_{i}$ is "expressiven $\ldots$. if meaningless actions (actions lacking linguistic meaning) must fare equally well, with respect to the factor. An "expressive theory of law" is a moral theory such that the moral factors $F_{l} \ldots F_{n}$ that collectively determine the moral status of a legal official's action include at least one expressive factor.

Id. at 1404 (citation and emphasis omitted).

${ }^{26}$ See id. at Part II (criticizing a variety of "expressive" theories, specifically weak $M$ expressive theories).

${ }^{27}$ General Restatement, supra note 4, at 1568.

${ }^{28}$ Id. at 1565 .

${ }^{29}$ Relatedly, my definition of "expressive theory" allows that such a theory can oblige a person to perform an action (or a series of actions) that is both $M$-expressive and falls under some non-expressive description. For example, the following is a kind of $M$-expressivism about punishment: the State should respond to criminal wrongdoing both by (a) condemning the offender, and (b) imposing hard treatment upon him. As I say quite clearly in my article, punishment expressivists might advocate either "Punishment $t_{E}$ " or "Punishment $t_{E, H}$ " See Skeptical Overview, supra note 1, at 1415 . Anderson and Pildes think I have defined "expressivism" such that the punishment expressivist is committed to Punishment ${ }_{E}$ rather than Punishment $t_{E, H}$, see General Restatement, supra note 4, at 1566-68, but this is a misconstrual of my definition. 
Equal Protection Clause, the Establishment Clause, and regulation, among others) have espoused theories that are either weak $M$ expressive theories or at least are plausibly understood as weak $M$ expressive theories. ${ }^{30}$ Numerous legal scholars seemingly attend, at least in part, to the linguistic meaning (speaker's meaning or sentence meaning) of legal decisions.

To ignore this fact-to say that "Adler confuses the concept of expression with the concept of communication" and that "[o]nce the concept of expression is understood as expressivists understand it, many of Adler's criticisms of expressive theories clearly miss the point ${ }^{\text {"31 }}$-is unfair on the part of Anderson and Pildes. Again: the term "expression" is profoundly ambiguous. "Expression" in one sense does refer to linguistic meaning, and many self-styled "expressivists" have used (or at least apparently have used) the term in that sense. Skeptical Overview attempts to advance the scholarly debate about expressivism by ruling out linguistic meaning theories, i.e., weak $M$-expressive theories. Once such theories are decisively and unambiguously rejected by the scholarly community-as I hope they will bewe can then move on to debate other types of "expressive" theories, e.g., ER-expressive theories, cultural impact theories, or Gricean signaling theories. General Restatement is an important contribution to this further debate, but it trivializes Skeptical Overview to suggest that no one could possibly mean, or have meant, to defend an $M$ expressive theory-that "expressivists" always and only have meant ERexpression (or some other kind of nonlinguistic meaning) when they employed the term "expressive." ${ }^{32}$

To summarize the discussion to this point: Skeptical Overview claims that no weak or robust $M$-expressive theory is correct. General Restatement either confirms, or is immaterial to, this claim unless it succeeds in defending a hybrid theory that is not only weakly $E R$ expressive, but also weakly $M$-expressive by containing at least one $M$ expressive factor.

Do Anderson and Pildes succeed in doing that? To begin, it is far from clear whether they intend to defend the kind of hybrid theory that would damage Skeptical Overview. Their lengthy and interesting

${ }^{30}$ See Skeptical Overview, supra note 1, at notes 73-76, 187-211, 230-34, 282-85, 294-97 and accompanying text.

s1 General Restatement, supra note 4, at 1565.

${ }^{32}$ Indeed, Pildes himself has elsewhere suggested that "expression" could refer to cultural impact rather than ER-expression or M-expression. See Skeptical Overview, supra note 1 , at 1499 n.449. 
analysis of legal (specifically constitutional) doctrine is entirely devoted to demonstrating the existence of ER-expressive factors, rather than a combination of $E R$-expressive factors and $M$-expressive factors. For example, they argue that state action can ER-express an improper conception of race and therefore violate the Equal Protection Clause, even if the action is not "stigmatic," i.e., even if it lacks a particular, disparaging, linguistic meaning:

\begin{abstract}
Suppose a State must ration access to gasoline during an energy crisis. It permits some drivers to fill up on certain days, other drivers on other days. The State might choose .... race of driver on ... grounds of administrative convenience. Such a law would be neither hostile nor stigmatic; it neither would impose a material inequality ... nor brand any race as inferior. Nonetheless, it evidently is unconstitutional... The deeper reason behind this doctrinal response would be that the too cavalier use of race itself raises constitutional concerns. By highlighting, without compelling justification, the racial distinctions that have historically divided us, such laws express an improperly divisive conception of the public.
\end{abstract}

Similarly, Anderson and Pildes take pains to show that the antiendorsement principle of Establishment Clause jurisprudence is concerned with ER-expression, not $M$-expression. They say that doctrine "clearly distinguishes the expressive meaning of state action from what state actors intended to communicate, and holds the State accountable for the former" ${ }^{34}$ and go on to provide the following example:

[B]y encouraging the placement of exclusively Christian religious symbols on public property during the Christmas season, state legislators might intend to communicate nothing more than collective joy for the time of year. The ordinance permitting these placements might even say: "To communicate our collective celebration of Christmas, we hereby authorize the placing of the following symbols in the city square." Their action, however, manifests their exclusive conception of the "we" with whom they are collectively celebrating. ${ }^{35}$

General Restatement's discussion of Dormant Commerce Clause and federalism doctrine is equally devoid of any demonstration that linguistic meaning, as opposed to ER-expression, is relevant to constitutional law. ${ }^{36}$

Nonetheless, there is some suggestion elsewhere in General Restatement that Anderson and Pildes are presenting a hybrid theory. In

\footnotetext{
${ }^{33}$ General Restatement, supra note 4, at 1537-38 (citation omitted).

${ }^{34} \mathrm{Id}$. at 1547 .

${ }^{35} \mathrm{Id}$. at 1550 .

${ }^{36}$ See id. at Part III.C..D.
} 
the Part on "The Nature of Expressive Harm," they state that "[c]ommunicative harms are a special class of expressive harms" ${ }^{337}$ and then elaborate:

[S]ocial relationships are constituted through shared public understandings and meanings, which are created through communication. This lets us grasp the special import of expressive harms constituted by the communication of negative or unjustified attitudes toward their victim. Communications can expressively harm people by creating or changing the social relationships in which the addressees stand to the communicator.

Similar statements occur later in the article. ${ }^{39}$ Let us call this the Expressive Harm Story ( $M$-Expressive Variant). The Expressive Harm Story ( $M$-Expressive Variant) says the following: (I) certain relationships between persons and state officials are constituted by the $M$ expressive actions of state officials; (II) some of those relationships are intrinsically harmful or beneficial for the persons involved; therefore, (III) state officials are morally required to perform (or refrain from performing) certain $M$-expressive actions.

The Expressive Harm Story ( $M$-Expressive Variant), if true, would indeed damage Skeptical Overview. Are Anderson and Pildes really advancing that syllogism, or are they rather advancing the Expressive Harm Story (ER-Expressive Variant), which says the following: (I') certain relationships between persons and state officials are constituted by the ER-expressive actions of state officials; (II') some of those relationships are intrinsically harmful or beneficial for the persons involved; therefore (III') state officials are morally required to perform (or refrain from performing) certain ER-expressive actions? I am not sure. The Expressive Harm Story (ER-Expressive Variant) does not damage my argument in Skeptical Overview, for reasons already discussed. For the (brief) remainder of this Reply, I will therefore assume that Anderson and Pildes are indeed advancing the Expressive Harm Story ( $M$-Expressive Variant) and attempt to respond to that claim.

As a preliminary matter, Anderson and Pildes accuse me of adopting a theory of linguistic meaning (of "communication," in their terminology) that makes it impossible for communications to make or break relationships.

\footnotetext{
${ }^{37}$ Id. at 1527. See generally id. at Part II.C.

${ }^{38} I d$. at 1528.

${ }^{39}$ See id. at $1571-75$.
} 
Adler does not see how communications (or failures to communicate) can establish or break social relationships.... We trace this failure to two intimately connected philosophical problems. First, Adler denies the very possibility of genuinely collective or shared understandings. Groups, he appears to think, cannot share beliefs in any robust, nonreductive sense. Second, he adheres to Grice's speaker-centered theory of meaning and Searle's speech-act theory of what we do in speaking .....

The Gricean and Searlean views fail to acknowledge that communication is a joint act-something we do together.... [The] view[s are] flawed because the completion of the communicative act requires that the addressee understand what the speaker has said. Absent such an understanding, the speaker has not communicated anything. ${ }^{40}$

My article does not claim that "[g]roups ... cannot share beliefs in any robust, nonreductive sense. ${ }^{41}$ All I say is that the actions of multimember bodies possess no speaker's meaning beyond whatever sentence meaning they possess. ${ }^{42}$ I do not take a position in Skeptical Overview on the possibility of group mental states, nor will I do so here; ${ }^{43}$ but I should note that my claim about the absence of legislative meaning beyond sentence meaning is quite consistent with a view that legislatures and other groups possess joint mental states. For example, one could say that the joint intention of the legislators in enacting a statute is to utter a statement the content of which equals the sen-

${ }^{40} \mathrm{Id}$. at $1571-72$.

${ }^{41}$ Id. at 1571.

${ }^{42}$ See Skeptical Overview, supra note 1, at 1389-93.

${ }^{43}$ In the course of arguing that the action of a legislature or some other multimember body lacks a speaker's meaning beyond whatever sentence meaning it may possess, I do assume that "[i]f every member of the legislature intends $M_{t}$ and solely $M_{1}$ by her enactment of the statute, then (at best) the legislature itself intends $M_{1}$ and solely $M_{1}$; it cannot intend $M_{2}$ if no member herself intends that." Id. at 1389. This assumption is quite consistent with the view (which I mean neither to endorse, nor to reject) that joint legislative mental states exist. The assumption is simply a reasonable constraint upon the content of any such states. Indeed, it appears that Anderson and Pildes would agree that a legislature cannot jointly intend $M_{2}$ if none of its members individually intend $M_{z}$. See General Restatement, supra note 4, at 1517 ("A group, $G$, has mental state $M$ if and only if the members of $G$ are jointly committed to expressing $M$ as a body.... The members of $G$ are jointly committed to expressing $M$ when each manifests a willingness to express $M$ together with the others, conditional upon the others manifesting a like willingness.").

I also state in passing that "legislatures ... do not possess mental states, independent of the mental states of the persons that make up these institutions." Skeptical Overview, supra note 1 , at 1389 . By this I simply mean the above assumption: that the legislature cannot intend $M_{2}$ if none of its members intends $M_{2}$ As the subsequent discussion in Skeptical Overview makes clear, I would have no particular objection to the claim that the legislature has a joint or collective intention to communicate $M$ just in case $M$ is the sentence meaning of its action. See $i d$. at 1391 . That claim is fully consistent with the focus upon sentence meaning adopted by Skeptical Overview. 
tence meaning of the text they enact.

As for the assertion by Pildes and Anderson that "the completion of the communicative act requires that the addressee understand what the speaker has said": ${ }^{44}$ First, I have been taking what Anderson and Pildes term "communication" to be identical to what I term "linguistic meaning." (If it is not, then General Restatement can do no damage to Skeptical Overview, since the kind of theories criticized in Skeptical Overview are linguistic-meaning theories, or $M$-expressive theories for short). Second, an action surely can possess linguistic meaning without being understood by the addressee. Whether or not this is true of speaker's meaning, it is surely true of sentence meaning. For example, if I yell "Yankee go home" from afar to a deaf New Englander, and neither he nor anyone else hears me, I have still performed a linguistically meaningful act-an act with sentence meaning-the content of which is determined by the linguistic conventions that map the phonemes for "Yankee go home" onto semantic content. ${ }^{45}$ Third, a theory of linguistic meaning (like mine) that does not make the addressee's understanding a necessary condition for the performance of a linguistically-meaningful act is fully amenable to the Anderson and Pildes assertion that linguistic meaning can be constitutive of interpersonal relationships-to the initial premise of what I have called the Expressive Harm Story ( $M$-Expressive Variant). All one has to say is this: it is constitutive of relationship $R$ between $S$ (peaker) and $A$ (ddressee) that (a) $S$ perform an action with linguistic meaning $M_{R}$ and (b) $A$ understand $M_{R^{*}}$. On the Anderson and Pildes view, which makes addressee understanding a component of linguistic meaning, the utterance of a particular linguistic meaning $M_{R}$ can be a necessary and sufficient condition for a particular relationship $R$; on the Adler view, the utterance of a particular linguistic meaning $M_{R}$ and addressee understanding of $M_{R}$ can be individually necessary and jointly sufficient conditions for a particular relationship $R^{46}$

\footnotetext{
${ }^{44}$ General Restatement, supra note 4, at 1572.

${ }^{45}$ See Skeptical Overview, supra note 1, at 1394-97 (summarizing and adopting conventionalist view of sentence meaning).

${ }^{46}$ Anderson and Pildes are also wrong in thinking that my theory of linguistic meaning or definition of $M$-expressivism somehow constrains $M$-expressivists to focus on either descriptive or declarative utterances. See General Restatement, supra note 4, at 1565-66. I clearly do not thus limit M-expressive theories. See Skeptical Overview, supra note 1 , at 1395 (stating that the article adopts a conventionalist view of sentence meaning because that theory "can accommodate multiple types of sentence meanings, including descriptive, directive, expressive, commissive, and declarative meaning); id. at 1420 (analyzing expressive theories of punishment, understood as theories that require state officials to "perform[] non-descriptive speech acts-[to utter] sen-
} 
In other words, Anderson and Pildes think that communicative utterances can be wholly constitutive of interpersonal relationships, while my view of linguistic meaning implies that communicative utterances can be partly constitutive of interpersonal relationships. In either event, the first premise of the Expressive Harm Story ( $M$-Expressive Variant) is possibly true: (I) certain relationships between persons and state officials are constituted by the $M$-expressive actions of state officials.

What I want to challenge about the Expressive Harm Story ( $M$ Expressive Variant) is not the first premise but the second: (II) some of the relationships constituted by the $M$-expressive actions of state officials are intrinsically harmful or beneficial for the persons involved. In effect, much of Skeptical Overview was devoted to challenging this claim. Take the case of a stigmatic utterance-an action by a state official with the linguistic meaning that some addressee $A$ is "inferior" or an "outsider." Anderson and Pildes, along with many other expressivists-scholars defending expressive theories of the Equal Protection Clause, scholars defending expressive theories of the Establishment Clause, and even some scholars writing in the area of punishment theory ${ }^{47}$-have suggested that a state official's stigmatic utterance about addressee $A$ is indeed intrinsically harmful for $A$. I will concede that a stigmatic utterance by a state official can create a new relationship (specifically, a legal relationship) for $A$. Let us call this new relationship the legal status of inferior. What I argued in Skeptical Overview, and will reassert here, is this: that legal status is not, in itself, harmful for A. Well-being is some function of preference, hedonic experience, and objective goods. Person $A$ might disprefer the status, but then again he might disprefer anything; insofar as legislators have a standing moral obligation, apart from $A$ 's preferences, not to perform a particular type of action (e.g., a linguistically meaningful action with a stigmatic content), some nonpreferential component of $A$ 's welfare or some moral factor other than welfare is being invoked.

As for hedonic experience: stigma is not itself an unpleasant mental state, but rather an utterance that may or may not cause an unpleasant mental state in $A$, depending on his emotional makeup, the cultural impact of the utterance, and so forth. Hedonists are not, without more, $M$-expressive theorists. A moral theory might include a

tences of condemnation or denunciation").

${ }^{47}$ See Skeptical Overview, supra note 1, at 1421-25, 1427-38, 1446-48 (citing, summarizing, and criticizing expressivist scholarship that is concerned with stigmatic utterances). 
basic factor or factors for hedonic experience, but those factors will refer to the hedonic states among the population produced by a given state action, not to its linguistic meaning. ${ }^{48}$

This brings us to the last possible component of welfare, namely, objective goods. Is $A$ objectively harmed when a state official utters a stigmatic statement about him (and he understands that statement) when $A$ is given the legal status of an inferior? My answer in the negative in Skeptical Overview hinged on the distinction between legal status and cultural or social status. I refer the reader to my article for the full argument, ${ }^{19}$ but it can be briefly summarized as follows: Person $A$ could have the cultural status of full equal (however precisely cultural status is analyzed, whether as a function of shared beliefs, or existing norms, or something else) even though his legal status is inferior. Law and social norms are distinct, and so, too, are legal and cultural status. Further, I deny that legal status (in contrast to cultural status) is an objective welfare good. Imagine a legal system in which legislators and other officials are generally held in low regard-as may be the case in our system and certainly is true in many others. To equate legal status and (objective) welfare is, I think, a mistake on a par with equating legal requirements and moral requirements. Just as law can lack moral authority, so too changes in legal status can lack a welfare impact.

Anderson and Pildes would not, I think, dispute my claim that a stigmatic utterance about $A$ is not necessarily harmful for $A(1)$ in virtue of $A$ 's preferences or (2) in virtue of $A$ 's hedonic experiences. They quite clearly sever their defense of the Expressive Harm Story from the contingent "psychological consequences" meaningful actions can produce, where the term "psychological consequences" (I take it) encompasses both preference-frustration and hedonic setbacks. So the crux of the (possible) ${ }^{51}$ debate between us is this: Is a stigmatic utterance by a state official about an addressee constitutive of an objective welfare-setback to that addressee? More precisely yet: Is a stigmatic utterance by a state official about an ad-

${ }^{48}$ See id. at 1462-65 (distinguishing between preference-based, hedonic, and objectivist accounts of well-being and arguing that the first two kinds of accounts do not support $M$-expressivism).

${ }^{49}$ See id. at 1421-25, 1427-38, 1446-48, 1466-73.

${ }^{50}$ General Restatement, supra note 4, at 1542-44.

51 I say "possible" because Anderson and Pildes may mean to defend the $E R$ Expressive Variant of the Expressive Harm Story and, in particular, to argue that stigmatic utterances are harmful in virtue of being ER-expressive. In this event, no debate has been joined. 
dressee constitutive of an objective welfare-setback to that addressee in virtue of being M-expressive (i.e., does it produce a setback that a merely ER-expressive action would not produce)?

On this issue, I see nothing in General Restatement that undermines the arguments presented in Skeptical Overview. Indeed, Anderson and Pildes fail to present a coherent and consistent response to those arguments. As I have already explained, it is not even clear whether they mean to defend the $M$-Expressive variant of the Expressive Harm Story-to claim that stigmatic utterances are objectively harmful to addressees in virtue of being $M$-expressive. Furthermore, General Restatement waffles between two mutually inconsistent strategies for defending the claim that stigmatic state utterances are objectively harmful to addressees. Sometimes, Anderson and Pildes seem to argue that stigmatic state utterances are constitutive of the cultural or social status of addressees:

The communication of attitudes creates social relationships by establishing shared understandings of the attitudes that will govern the interactions of the parties. Consider how this works in the context of state action. A State may communicate its contempt for blacks by requiring the racial segregation of public facilities. Racial segregation sends the message that blacks are untouchable, a kind of social pollutant from which "pure" whites must be protected.... Once people share an understanding that segregation laws express contempt for blacks, these laws constitute blacks as an "untouchable," stigmatized caste.

Similarly, they state that:

Citizens acting together through the State are already regarding nonadherents as outsiders when they endorse religion. This collective action in itself constitutes a change in the citizenship status of nonadherents, whether or not citizens individually believe such a change is justified. Citizenship is a legal status, not a matter determined by the individual opinions prevalent in the culture. ${ }^{53}$

In these passages, the suggestion seems to be that a person's social status as an outsider, a member of a lower caste, is directly and noncontingently created by a legislative promulgation declaring her to be lower status, since this promulgation represents the collective action of the citizenry. Yet, at other points, Anderson and Pildes seem to concede that legal versus social status are distinct and to argue instead that stigmatic utterances are (necessarily) objectively harmful to ad-

${ }^{52}$ General Restatement, supra note 4, at 1528; see also id. at 1544 ("[L]egal communications of status inferiority constitute their targets as second-class citizens.").

${ }^{53} I d$. at 1548. 
dressees without (necessarily) lowering their cultural or social status. ${ }^{54}$

Again: legal and social status are distinct. I cannot possibly demonstrate that here but will simply reference the burgeoning scholarly literature on law and norms, which is cited and discussed in Skeptical Overview. ${ }^{55}$ Person A's social position, or status, or class is a meaningful and important concept that arguably does have a close relationship to $A$ 's objective welfare-as a prerequisite for $A$ 's self-respect $t^{56}$-but that has no constitutive connection (not even a partial one) to $A$ 's legal position, including whatever stigmatic utterances state officials may have uttered concerning $A$. Note that this view is consistent, not just with the recent scholarship focused on the disjunction between law and norms, but also with the older, jurisprudential scholarship claiming that a legal system can exist without the content of legal officials' utterances being approved or valued by those subject to the system. $^{57}$

As for the claim that stigmatic utterances which leave A's social status fully intact nonetheless objectively harm him: why would they? Start with the case where some private person $B$, who lacks social influence, utters a disparaging statement about $A$ and where $A$ does not disprefer the statement or suffer bad feelings as a result. Surely in that case the statement is not an intrinsic welfare setback for $A^{58}$ Now amend the case, so that $B *$ is a state official who lacks social influence and utters a disparaging statement about $A$ (which neither causes a hedonic setback for $A$ nor is dispreferred by him). Why insist that $B *$ s statement is intrinsically bad for $A$ even though $B$ 's is not? To be sure, constitutional doctrine might prohibit $B *$ from making the statement-doctrine might focus on the content of $B$ *s statement, not the harm that results to $A$-but, if so, that is because a doctrine focused on stigma and linguistic meaning is more administrable than a doctrine focused on cultural impact, not because stigma has intrinsic

\footnotetext{
54 See id. at 1544 n.107, 1545.

55 See Skeplical Overview, supra note 1, at notes 44, 353-74 and accompanying text.

${ }^{56} \mathrm{See}$ id. at $1475-76$.

${ }^{57}$ See generally H.L.A. HART, THE CONCEPT OF LAW (1961).

${ }^{53} B$ 's statement might, conceivably, be morally problematic even though it does not harm $A$. For example, it might contain a falsehood, such that $B$ has breached the duty to refrain from lying by uttering the statement. I considered this possibility in my article but will not discuss it here, since Anderson and Pildes have framed their challenge to Skeptical Overview by focusing on expressive harms. See Skeptical Overview, supra note 1, at Part III (providing a general argument against $M$-expressivism, directed both against the view that $M$-expression is harmful and against the view that $M$-expression is morally significant apart from its effect on welfare).
} 
moral (welfare) significance. ${ }^{59}$

It is also possible that the case of stigma is not exemplary. That is, it is at least possible that (a) a stigmatic state utterance is not intrinsically harmful for the addressee but (b) the Expressive Harm Story ( $M$ Expressive Variant) remains true, since some kind of $M$-expressive action by state officials other than stigma is intrinsically harmful. Yet expressive theorists (at least theorists concerned with the harmful cast of state expression) have typically trained their attention upon stigma, and Anderson and Pildes are no exception. Their defense of the Expressive Harm Story is indeed centered on the example of stigmatic state utterances-utterances that change legal status, that declare or describe the addressee as an inferior or otherwise lower his legal position-and this is not surprising. For if stigmatic utterances are not intrinsically harmful for addressees, then intuitively it would seem to follow a fortior $i$ that other types of $M$-expressive state utterances are not. Anderson and Pildes do not rebut, or attempt to rebut, this inference. Nor, I have already suggested, do they succeed in showing that stigmatic utterances are intrinsically harmful (either by changing social status, or without changing social status). I therefore conclude that General Restatement does not undermine Skeptical Overview. My argument against $M$-expressivism remains intact.

But-once more-the main aim of General Restatement is not to rehabilitate $M$-expressivism. It is to present an entirely new kind of expressivism, one that I neither criticized nor endorsed in Skeptical Overview and that I have studiously refrained from considering here: $E R$ expressivism. ${ }^{60}$ This is a novel, interesting, and ambitious theory. Anderson and Pildes are to be congratulated for having developed it, and it is this theory, along with other nonlinguistic versions of expressivism (for example, cultural impact theories or Gricean signaling theories), that now merits close scholarly scrutiny and debate.

${ }^{59}$ See id. at 1437 (distinguishing between constitutional doctrines and the moral factors that doctrines implement).

${ }_{60}$ Anderson and Pildes suggest that, in other scholarship, I have actually committed myself to some variant of expressivism by arguing that constitutional rights are "rights against rules." See General Restatement, supra note 4, at 1520-21, 1569 (discussing Matthew D. Adler, Rights Against Rules: The Moral Structure of American Constitutional Law, 97 MiCH. L. REv. 1 (1998)). But that article defined "rule" as an enacted, legal rule, see Adler, supra, at 17 -not as an underlying legislative purpose or attitude, $c f$. General Restatement, supra note 4, at 1520-21, 1569-and thus is in no way committed to an expressivist view of constitutional law. See also Matthew D. Adler, Personal Rights and. Rule-Dependence: Can the Two Co-Exist?, 6 LEGAL THEORY (forthcoming Dec. 2000) (reiterating that constitutional rights are "rights against rules" and rejecting an expressivist account of this feature of rights). 